\title{
Analysis of Implementation of EWSS (Early Warning Score Systems) Against AvLos (Average Length of Stay) and the Trust of Patients in Inpatient Installation at Jombang General Hospital
}

\author{
Sutikno $^{1}$, Sandu Siyoto ${ }^{2}$, \\ Byba Melda Suhita ${ }^{2}$ \\ ${ }^{1}$ Magister Study, Faculty of health \\ sciences community Institut Ilmu \\ Kesehatan STRADA Indonesia \\ ${ }^{2}$ Lecturer of Institut Ilmu \\ Kesehatan STRADA Indonesia \\ Email: \\ soetikno2015@gmail.com
}

Received: October 12, 2019

Accepted : February 13, 2020

Published : May 12, 2020

\begin{abstract}
Hospitals are required to always improve the quality of service provided to patients. These challenges have forced the hospital to develop its ability to manifest in various aspects of health care quality responsible. One of them by applying the assessment and early detection in patients kegawatan as well as the critical state of activation becomes very important. Quick and proper response to a nurse against the worsening conditions of patients giving a great impact to the quality of the quality of service provided. The purpose of this research is to analyze the implementation of Early Warning systems (EWSS) Score against AvLOS and trust patients in Inpatient installation at Jombang General Hospitals. The research design was analytic observational with a quantitative approach. Research variables i.e. implementation of EWSS as independent variables. AvLos and trust patients as the dependent variable. The population of this entire research nurses in Inpatient installation at Jombang General Hospitals as much as 135 nurses, patients and families of patients who are being treated in Inpatient installation at Jombang General Hospitals Jombang. Samples taken with the cluster random sampling technique as much as 101 respondents. Data is collected with instruments ceklist and processed in coding, editing, tabulating and scoring as well as tested with logistics regression test. Logistic regression results indicate that partially and simultaneously show that the value of $p$ values $<0.05$ so that there were the implementation of Early Warning systems (EWSS) Score against AvLOS and trust of the patient, and the simultaneous influence of $83.2 \%$. The existence of implementation of EWSS in patients with good then early detection and response officers can be done in a proper and effective against the condition and the healing of patients and can shorten the day care patients, so that it can affect the confidence and trust family and patient in receiving health services in the hospital.
\end{abstract}

Keywords: Early Warning Score System (EWSS), AvLos, Trust

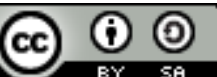

This is an open-acces article distributed under the terms of the Creative Commons Attribution-ShareAlike 4.0 International License. 


\section{INTRODUCTION}

Hospital as health service service order giver has a strategic role in an attempt to improve public health degrees in Indonesia demands will quality health services give effect at the same time challenge for the hospital to survive. In addition, in the system of national standards accreditation issue 1, hospitals are required to always improve the quality of service provided to patients. These challenges have forced the hospital to develop its ability to manifest in various aspects of health care quality responsible (Sumijatun, 2009).

In improving the quality of service, the nursing personnel should be trained to be able to recognize and berespon to change the condition of the patient. Nurses as executor in providing professional nursing care should do the studies are focused and observing the vital signs to be able to assess and find out the risk of the occurrence of a worsening of the patient's condition early. The worsening conditions of patients in hospitals are often preceded by signs of abnormal vital signs or other physiological (Jones, et al., 2013). Early detection, punctuality and competence in clinical response is the determining factor of Clinical outcomes in acute diseases (Royal College of Physicians, 2012). In the world have introduced a system of scoring early detection or early warning system to detect any worsening of the State of the patient with the application of the Early Warning Scoring. EWS has been applied to many hospitals in the United Kingdom especially the National Health Service, the Royal College of Physicians has recommended that the National Early Warning Score (NEWS) as standards for the assessment of acute diseases, and used on team multidsiplin (NHS Report, 2012).

Early Warning Scoring Systems is a physiological skoring system commonly used in medical surgical unit before patients experience the condition kegawatan. Early Warning Scoring Systems is a system request assistance to resolve health problems the patient early based on the assessment of the patient's circumstances change through systematic observation of all changes of Physiology patients. EWSS are varied in design and inclusion mainly on physiological parameters were assessed. The simplest parameters used to assess the worsening condition of the patient can be judged from the vital signs. The Hamilton Early Warning Score (HEWS) using a combination of blood pressure (systolic), heart rate, respiration, temperature and level of consciousness (AVPU), oxygen saturation, and the use of oxygen (Xu M, Tam B, Thabane L, et al., 2015).

The role of monitoring and early detection against kegawatan as well as the critical state of activation becomes very important. Quick and proper response to a nurse against the worsening conditions of patients giving a great impact to the quality of the quality of service provided. From clinical negligence 1084 reported in the United Kingdom during the year 2005 (National Patient Safety Agency, 2007), 576 potentially avoidable death incident, 425 incident of death which occurs in acute and 64 deaths that occur due to a decrease in the condition of the patients not responded quickly (Beaumont, et al., 2008). It can be badly family both physically and psychologically. Costs for clinical negligence claims in the United Kingdom during the year 2008-2009 reached $£ 769$ million. In America, the cost of claims from preventable side effects is estimated to be between US \$17 and \$29 billion per year (Thomas et al., 1999). Besides research conducted by Ahmad, et al (2017) shows that there is a positive correlation between the score ViEWS with worsening patient access block in the dr. Iskak General Hospitals of Tulungagung.

Every hospital inpatient services, hosts generally have statistical data as a measurement of quality of service. One of these quality indicators i.e. AvLOS (Average Length of Stay). AvLOS (Average Length of Stay) is the average long-patient a patient. The ideal AvLOS value between 6-9 days (of health RI, 2005). Based on the preliminary studies carried out at the installation of Inpatient installation at Jombang General Hospitals, obtained the data that the implementation is done before patients AvLOS EWSS are of 10.13. It indicates that the value is larger than the standard AvLOS ideal set forth by Health RI.

The nurse as care giver providing service by doing a daily study and monitor the State of the patient. When there is a worsening of form, the first person who knows is a nurse. When a nurse is able to show it against the patient, it will be able to create a sense of trust from either the patient or the family to the nurse. Consumer confidence will arise because there is a belief that the parties involved will give you consistent quality, honest, and responsible. These beliefs will cause the good relationship between the parties involved exchanges. While Anderson and Narus (1990) in Akbar Mohammad Muzahid, et al (2009) if either party believes that the other party will bring positive results for the first party, trust can be developed. 
When the trust is already created, then customer satisfaction will be created anyway. Creation of customer satisfaction may provide some benefits, such as the relationship between the company and its customers become harmonious. The existence of a good quality of service in a company then it is going to create satisfaction for our customers. After consumers were satisfied with the product or service received, consumers will compare the service given. If consumers really are satisfied, they will buy the anniversary as well as giving recommendations to others to buy in the same place (Tjiptono, 2011). Based on the description above, then the background of researchers interested in examining the influence of implementation of EWSS against AvLOS and trust of patients in Inpatient installation at Jombang General Hospitals

\section{METHODS}

The research design was analytic observational with a quantitative approach. Research variables i.e. implementation of EWSS as independent variables. AvLos and trust patients as the dependent variable. The population of this entire research nurses in Inpatient installation at Jombang General Hospitals as much as 135 nurses, patients and families of patients who are being treated in Inpatient installation at Jombang General Hospitals Jombang. Samples taken with the cluster random sampling technique as much as 101 respondents. Data is collected with instruments ceklist and processed in coding, editing, tabulating and scoring as well as tested with logistics regression test. Research will be carried out from the start to the preparation of the proposed research to the examination Council of the thesis. Implementation started in October - November 2018.

a. Univariate Analysis.

Assessment of the implementation of EWSS and trust patients was obtained from answers to each question contained in the questionnaire. Of the respective score finally aggregated so that the total score obtained. On variable implementation of EWSS, the total score has a limit of the interval between $0-20$, with assessment criteria:

1): Score $T \geq T$ Mean (average value)

2): Score $\mathrm{T} T<$ Mean (average value)

In the variable trust patients, interpretation of the score value-based views of the average score of each respondent. With the provisions of:

1) Trust: Score $T \geq T$ Mean (average value)

2) little faith: Score $T \mathrm{~T}<$ Mean (average value)

b. Bivariat Analysis

To find out whether or not there is a relationship between variables used spearman rho test because the scale used is the ordinal data.

Testing conducted with the use of a significant level of $\alpha=0.05(5 \%)$. Acceptance or rejection of the hypothesis can be done with the criteria:

1) if significant value $0.05>$ then $\mathrm{H} 1$ rejected this means independent variable does not influence significantly to the dependent variable.

2) if significant value $\leq 0.05$ then $\mathrm{H} 1$ accepted this means partially independent variables have significant influence towards the dependent variable.

\section{RESULT}

\section{Multivariat Analysis}

\section{1) Partially Analysis}

Table 1. Logistic regression analysis of partially Between implementation of EWSS Avlos and trusts with patients in Inpatient installation at Jombang General Hospitals November $2018(\mathrm{n}=101)$

\begin{tabular}{ccccccc} 
Variabel & B & S.E & Wald & df & Sig & Exp (B) \\
\hline Avlos & 1,789 & 0,391 & 20,950 & 1 & 0,000 & 2,167 \\
\hline Trust Of Patient & 1,530 & 0,789 & 3,758 & 1 & 0,003 & 4,616 \\
\hline Trust of Family & 1,360 & 0,816 & 2,195 & 1 & 0,009 & 1,433 \\
\hline
\end{tabular}


Based on the results in table 1 shows in partial implementation of EWSS can affect changes in the dependent variable i.e. (AVlos, patient trust and family trust) with the value significance of 0.000 to Avlos, 0.003 to 0.009 to patient and trust family trusts. Based on the value of B (the coefficient of each variable) indicate that both models the third variable coefficient value not equal to $0(=1.789$ Avlos, patient Trust $=1.530$, and family trusts $=1.360$ ) so that both models are said to be appropriate in the calculation statistics. On the value of the wald test result shows the value partially at variable value equal to wald Avlos 20.950 with standard error value and 0.391 wald on the trust patients of 3.758 with standard error of 0.789 family trust, and on the value of wald of 2.195 with standard error of 0.816 . These results indicate that the influence of partially variable Avlos highs than the trust of patients.

Views of the value of the Exp (B) obtained the opportunity the implementation of EWSS against Avlos of 2.167 means the better implementation of EWSS then days of inpatient care will be increasingly short of 2.167 times, on patient trust obtained the value of 4.616, so it is stated that the better the implementation of EWSS then will further improve patient confidence of 4.616 times, while on a family trust shows the value of 1.433 so this shows that the better the implementation of EWSS then will be more able to improve the family trust of 1.433 times. The results of this research show that partially or alone - its own independent variable may affect the occurrence of the dependent variables because the value significance $<0.05$.

\section{2) Simultaneously analysis}

Tabel 2. Logistic regression analysis simultaneously or synchronously Between implementation of EWSS Avlos and trusts with patients in Inpatient installation at Jombang General Hospitals November $2018(\mathrm{n}=101)$

\begin{tabular}{|c|c|c|c|c|c|}
\hline \multirow{3}{*}{ 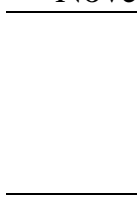 } & \multirow{3}{*}{ Observed } & & \multicolumn{3}{|c|}{ Predicted } \\
\hline & & & \multicolumn{2}{|c|}{$\begin{array}{c}\text { quality of the physical } \\
\text { environment }\end{array}$} & \multirow{2}{*}{ Percentage Correct } \\
\hline & & & Less & Good & \\
\hline \multirow{3}{*}{ Step 0} & \multirow{2}{*}{$\begin{array}{c}\text { quality of the physical } \\
\text { environment }\end{array}$} & Less & 0 & 18 & .0 \\
\hline & & Good & 0 & 18 & 100.0 \\
\hline & \multicolumn{2}{|c|}{ Overall Percentage } & & & 50.0 \\
\hline
\end{tabular}

Based on the results in table 2 show that the independent variable affect simultaneously or together on the dependent variable, indicated by the value of the overall percentage of 83.2 from these data can be known also that the values predictions can predict the variables with a level of truth of $83.2 \%$ (bigger than when it involves constants). Application of classification based on the classification of EWSS indicate less shows the influence of $79.1 \%$ and on the classification of the good shows the influence of $86.2 \%$. The table also shows that of the 101 respondents, there were $84(34+50)$ respondents the right pengklasifikasiannya by regression logistics model. Based on the value significance of obtained values of $\mathrm{p}$ value 0.05 so simultaneously < variable implementation of EWSS Avlos and trusts to patients.

\section{DISCUSSION}

A. The implementation of Early Warning systems (EWSS) Score in Inpatient installation at Jombang General Hospitals

Based on the data in the diagram that the application data obtained Early Warning Score systems (EWSS) have done well as much as 58 respondents (57\%). Based on the data in the diagram that the data obtained Early Warning Score systems (EWSS) based on the grading of patients obtained data most of the patients included in the grading of white as much as 45 patients (44\%), green grading as many as 29 patients (29\%), grading to yellow as much as 19 patients (19\%) and grading Red 8 patients (8\%).

Early Warning Scoring System is a system of physiological skoring commonly used in medical surgical unit before patients experience the condition kegawatan. Skoring EWSS are accompanied by actions based on the results of the skoring algorithm of the study patients (Duncan \& McMullan, 2012). Early Warning Score systems (EWSS) is a systematic approach that uses skoring to identify a person's condition changes and decide the next steps that have to be ironed 
out. This assessment is done on adults (over the age of 16 years), not for children and pregnant women (Royal College of Physicians, 2012).

Application of Early Warning Scoring System (EWSS) committed by officers or nurses in HOSPITALS can be categorised Stubs have been implemented or are being implemented properly. The existence of the application of the Early Warning Scoring System (EWSS) good menunukkan that the medical services provided by HOSPITALS Stubs can be said quite well because the nurse on duty or other health workers try to do quick and proper response against worsening conditions of patients giving a great impact to the quality of the quality of service provided. This situation occurs because the officer had already obtained training or knowledge of the procedures for the application of the Early Warning Scoring System (EWSS) pretty well and how its implementation against patients so that they are able to carry out actions to provide the services and the proper handling and quickly to patients. This can be seen in patients with grading green nurses carry out reporting to the nurse in charge (the primary nurse/keep your head) who is in charge of the shift on that day, and will determine whether it doctor reported to pelu ( or go directly to DPJP), and in patients with grading or monitoring observations carried out yellow every 1-2 hours and also reported on the DPJP/Resident in charge will determine the therapy or clinical action that can be performed in accordance with the patient's clinical so patient handling can be implemented with more precise and effective.

\section{B. AvLOS in Inpatient installation at Jombang General Hospitals}

Based on hospital data didapakan AvLOS most patients have been undergoing treatment for 6 days as many as 38 respondents $(37 \%)$ and a small part for $>6$ days as many as 28 respondents $(28 \%)$.

AVLOS according Health RI (2005) is the average long-patient a patient. This indicator gives an addition level of efficiency, can also provide an overview of the quality of service, when applied in specific diagnosis can be made into things that need further observation. In general the value of the ideal AVLOS between 6-9 days (of health, 2005). AVLOS according to Huffman (2012) is "The average inpatient stay of hospitalization discharged during the period under consideration". According to Wuryanto (2009) the difference in skills and decided to do an act between a different doctor will affect the long day care patients. In addition, the amount of power the doctor nor the nurse also played an important role in dealing with patients.

The results of this research show that the number of Inpatient installation at Jombang General Hospitals Avlos shows the value of a good number of days a patient lives by rawat needs faster. This indicates that the officer's service in hospital medical officer in this case either the doctor or nurse has given maximum service because of the number of days a patient more quickly showed a good service quality indicator and efisensi costs incurred by the patient or the hospital so that the State can provide a positive perception on patients and improve patient visits to the hospital. The clerk at the Inpatient installation at Jombang General Hospitals strives to provide excellent service and quality bermut can be shown with the long day care a short and also the condition of patients who started there increased until the patient can undergo treatment at home. This is the commitment of management and employees of the Inpatient installation at Jombang General Hospitals that are working to improve the quality and the degree of public health through health service quality and quality-oriented healing patients.

\section{The Trust of patients and families in Inpatient installation at Jombang General Hospitals}

Based on the trust or confidence of the patient data was obtained by most patients of the nurse in charge of as much as 55 respondents (54\%). Based on the trust or confidence of the patient's family obtained the data most of the patient's family believe against nurses who served as many as 63 respondents $(62 \%)$.

The trust is part of attitude. Attitude consists of aspects of cognitive, affective and konasi. The trust was formed in the cognitive aspects (Azwar, 2010). Attitude itself is a passive behaviour which is invisible, but still it will affect Active behavior visible (Sarwono, 2012). With the existence of a trust, an individual will be willing to take risks that may occur in conjunction with other parties (Mayer, 2005). 
The results of this study showed that the confidence of patients and families against the officers or nurses in hospitals is still pretty good Stubs. This happens because the nurse has already provided the skills in performing nursing care in patients and families so that they can apply these skills have in providing health services on patients and families undergoing Inpatient installation at Jombang General Hospitals. The presence of skills and good communication from the nurse makes the patient and family to feel trust and confident against the handling of the health problems that are being experienced so as to speed up the process of recovery of the patient's condition with more maximum. In addition the presence of positive support from families making patients have higher motivation in order to get well soon and return home in good health. The presence of families and patients who still do not have the credentials to the service of nurses in Inpatient installation at Jombang General Hospitals will affect the patient's healing process, because the services provided by the clerk will remain good despite the lack of service has been carried out in accordance with the applicable procedures.

\section{Influence the implementation of Early Warning systems (EWSS) Score against AvLOS in Inpatient installation at Jombang General Hospitals.}

Based on the results shows the significance value $=0.000<0,05$ so that accepted $\mathrm{H} 1$ it means there is a connection between the implementation of EWSS AVLos with patients. Based on the value of the correlation coefficient shows the value of 0.558 this indicates that the influence of the variables are independent of the dependent variable are strong enough.

Early Warning Scoring Systems is a physiological skoring system commonly used in medical surgical unit before patients experience the condition kegawatan. Early Warning Scoring Systems is a system request assistance to resolve health problems the patient early based on the assessment of the patient's circumstances change through systematic observation of all changes of Physiology patients. EWSS are varied in design and inclusion mainly on physiological parameters were assessed. The simplest parameters used to assess the worsening condition of the patient can be judged from the vital signs. The Hamilton Early Warning Score (HEWS) using a combination of blood pressure (systolic), heart rate, respiration, temperature and level of consciousness (AVPU), oxygen saturation, and the use of oxygen (Xu M, Tam B, Thabane L, et al., 2015). The role of monitoring and early detection against kegawatan as well as the critical state of activation becomes very important. Quick and proper response to a nurse against the worsening conditions of patients giving a great impact to the quality of the quality of service provided. From clinical negligence 1084 reported in the United Kingdom during the year 2005 (National Patient Safety Agency, 2007), 576 potentially avoidable death incident, 425 incident of death which occurs in acute and 64 deaths that occur due to a decrease in the condition of the patients not responded quickly (Beaumont, et al., 2008).

Application of Early Warning Scoring Systems (EWSS) are implemented correctly will affect the patient's healing process, because with a good implementation of EWSS. Long Treated a patient is calculated by subtracting the date reduced still comes out in a month (add the following day when over the edge of the moon. Patients in and out on the same day can be calculated one day. Figures are more affected on quality AvLOS health services provided by medical personnel as well as the supported equipment and facilities available at the hospital. So if the quality of care and health services provided by medical personnel that enhanced directly will raise the number of visits inpatient patients to the hospital. This shows that the implementation of the Early Warning Scoring Systems Officer can do better with early detection so that actions or circumstances of the patient handling can be done more effectively and efficiently and can affect the long day care patients become shorter, with long days short so rawat can show indication of good service so that it can affect the satisfaction of patients and can increase the amount of inpatient visits.

E. The influence the implementation of Early Warning Score systems (EWSS) against the trust of patients and families Inpatient installation at Jombang General Hospitals

Based on the results table 1 shows the significance value $=0.000 \mathrm{H} 1$ so that 0.05 accepted $<$ means there is a connection between the implementation of EWSS Trust with patients. Based on the value of the correlation coefficient shows the value 0.419 this indicates that the influence of 
the variables are independent of the dependent variable are strong enough. Based on the results in table 4.16 shows the significance value $=0.001$ so that $<0.05$ it means received $\mathrm{H} 1$ there is a connection between the implementation of EWSS Trust with patients. Based on the value of the correlation coefficient shows the value of 0.323 this indicates that the influence of the variables are independent of the dependent variable are strong enough.

According to Gurviesz \& Korchia (2011) States development trust especially beliefs, should be a fundamental component of a marketing strategy that is intended to lead to the creation of a genuine customer relationships. To build trust does require a short time, and requires sufficient meetings with intensity customers. Mowen and Minor (2012) declare a person looking for products and services that will solve problems and meet their needs in other words has the right attributes provides benefits that can be known. The relationship between the attributes and benefits of this type of trust describes the latter. The trust attributes the benefit is the perception of consumers about how far a certain atribu produce, or providing certain benefits.

The trust of patients and families is one of the things that are important in the marketing services especially health services. The existence of the services provided by the hospital can demonstrate quality service and quality. This shows that the confidence of patients and families in the Jombang public hospital mostly shows good confidence and on the family also showed the existence of a trust. The existence of the trust from both the families indicated that implementation of EWSS in the care of a patient gives a positive perception on patients and families giving rise to trust or confidence is good. Including the family stated that they had a good and complete explanation about the procedure of granting the Act or condition of patients, perawaa always keep communication or relationship with the patient and family are good so the anxiety experienced families on the condition of patients with critical chronic diseases and can be reduced, the nurses also provide cpeat response against complaints by families or patients and handling are done by officers are also skilled and Deft. It is these circumstances which affected the confidence and satisfaction of patients receiving services at the Inpatient installation at Jombang General Hospitals.

\section{F. Influence of implementation of Early Warning systems (EWSS) Score against AvLOS and trust patients In Inpatient installation at Jombang General Hospitals}

Based on the results in table 2 shows in partial implementation of EWSS can affect changes in the dependent variable i.e. (AVlos, patient trust and family trust) with the value significance of 0.000 to Avlos, 0.003 to 0.009 to patient and trust family trusts. Based on the value of B (the coefficient of each variable) indicate that both models the third variable coefficient value not equal to $0(=1.789$ Avlos, patient Trust $=1.530$, and family trusts $=1.360)$ so that both models are said to be appropriate in the calculation statistics. On the value of the wald test result shows the value partially at variable value equal to wald Avlos 20.950 with standard error value and 0.391 wald on the trust patients of 3.758 with standard error of 0.789 family trust, and on the value of wald of 2.195 with standard error of 0.816 . These results indicate that the influence of partially variable Avlos highs than the trust of patients.

Views of the value of the Exp (B) obtained the opportunity the implementation of EWSS against Avlos of 2.167 means the better implementation of EWSS then days of inpatient care will be increasingly short of 2.167 times, on patient trust obtained the value of 4.616, so it is stated that the better the implementation of EWSS then will further improve patient confidence of 4.616 times, while on a family trust shows the value of 1.433 so this shows that the better the implementation of EWSS then will be more able to improve the family trust of 1.433 times. The results of this research show that partially or alone - its own independent variable may affect the occurrence of the dependent variables because the value significance $<0.05$.

Based on the results in table 4.18 shows that independent variable affect simultaneously or together on the dependent variable, indicated by the value of the overall percentage of 83.2 from these data can be known also that the values predictions can predict the variables with a level of truth of $83.2 \%$ (bigger than when it involves constants). Application of classification based on the classification of EWSS indicate less shows the influence of $79.1 \%$ and on the classification of the good shows the influence of $86.2 \%$. The table also shows that of the 101 respondents, there were $84(34+50)$ respondents the right pengklasifikasiannya by regression logistics model. Based on 
the value significance of obtained values of $\mathrm{p}$ value $<0.05$ so simultaneously variable implementation of EWSS Avlos and trusts to the patient.

Early Warning Score systems (EWSS) is kegawatdaruratan service development in patients who are hospitalized, which served as a means of early detection so that in the event of a decline in the condition of the patient can be known in advance can be handled faster. EWS based upon the assessment of the patient's circumstances change through systematic observation of all changes to the physiology of the patient. This system is the concept of proactive approaches to improve patient safety and clinical outcomes of patients with a better standardization of approaches to assessment and assign a simple physiological parameter skoring. Continuity of service to be done both in a stable state of the patient or when the patient is in poor condition. Early detection, timeliness respond, clinical response and competency is a set of activities that must be performed to optimize clinical outcomes (Tirtionegoro, 2016). Early Warning Score systems (EWSS) using the simple approach based on two main requirements are: a systematic method to measure physiologic parameters is simple on all patients to allow early identification of patients who experience acute illness or condition is worsening, and; clear definition of the precision of the urgency and scale of the required clinical response, adapted to the severity of the disease (McGaughey, 2009). One of the purposes of the application of EWSS is to detect early stage clinical conditions decreased patient swlama in care at the hospital so that the handling of patients can be done properly and quickly.

The results of this study suggest that with the implementation of EWSS during patient care in inpatient care affects the confidence of patients and families on the officer or nurse so that they accept and respond to actions taken by nurses and affect the speed of response of nurses on patient handling in doing so speeds up healing. Confidence and a feeling of calm which is accepted by the family and the patient caused the patient and family feel of the services received in a hospital.

\section{CONCLUSSION}

The application of the Early Warning Score systems (EWSS) in Inpatient installation at Jombang General Hospitals already done well as much as 58 respondents (57\%).

Service assessment Index based on AvLOS hospital patients in Inpatient installation at Jombang General Hospitals shows most patients have been undergoing treatment for 6 days as many as 38 respondents (37\%) and a small part for 6 days as many as $28>$ respondents $(28 \%)$.

Trust or the trust of patients in Inpatient installation at Jombang General Hospitals Jombang obtained data most patients of the nurse in charge of as much as 55 respondents (54\%).

Trust or family trust of patients in Inpatient installation at Jombang General Hospitals obtained data most of the patient's family believe against nurses who served as many as 63 respondents (62\%).

There is the influence of the application of the Early Warning Score systems (EWSS) in Inpatient HOSPITALS Jombang AvLOS and trust towards patients with value of significance $0.05<$.

\section{REFERENCE}

Ahmad. dkk. (2017). Efektifitas Vitalpac Early Warning Scoring Sebagai Deteksi Dini Perburukan Pasien Access Block Di IGD dr. Iskak Tulungagung. J.K Mecehecephalon Vol. 3 No 2017.

Duncan, K., \& McMullan, C. (2012). Early Warning System. Philadelphia: Lippincott Williams \& Wilkins.

Huffman, EK. (2012). Health Information Management. Phisichian Record Company Berwin Illionis, USA.

Jones, D., Mitchell, I., Hillman, K., \& Story, D. (2013). Defining clinical deterioration. Resuscitation, 84(8), 1029-1034.

National Health Service. (2012). Critical care outreach: progress in developing services.

Royal College of Physicians of London. (2012). NHS Early Warning Score (NEWS). 
Siyoto, S., Sodik, M., A. (2015). Dasar Metodologi Penelitian. Yogyakarta: Literasi Media Publishing.

Siyoto, S., Wardani, R. (2016). Dasar Statistik Untuk Kesehatan. Yogyakarta: Literasi Media Publishing.

Tjiptono, \& Fandy. (2011). Pemasaran Jasa. Malang: Bayumedia Publishing.

Wuryanto, S. (2012). Pengantar Statistik Pelayanan Kesehatan. Materi Pada Pelatihan Manajemen Rekam Medis dan Informasi Kesehatan. Yogyakarta: PORMIKI DIY.

Xu, M., Tam, B., Thabane, L. et al. (2015). A protocol for developing early warning score models from vital signs data in hospitals using ensembles of decision trees. BMJ Open 2015;5:e008699. doi:10.1136/bmjopen-2015-008699 